\title{
Urgences
}

\section{Alors ? (seconde notule introductive)}

\section{Renald Bérubé et André Gervais}

Numéro 19, janvier 1988

Le tour du texte

URI : https://id.erudit.org/iderudit/025446ar

DOI : https://doi.org/10.7202/025446ar

Aller au sommaire du numéro

Éditeur(s)

Urgences

ISSN

0226-9554 (imprimé)

1927-3924 (numérique)

Découvrir la revue

Citer ce document

Bérubé, R. \& Gervais, A. (1988). Alors ? (seconde notule introductive). Urgences, (19), 73-74. https://doi.org/10.7202/025446ar d'utilisation que vous pouvez consulter en ligne.

https://apropos.erudit.org/fr/usagers/politique-dutilisation/ 


\section{Alors? \\ (seconde notule introductive)}

Parfois, ponctuellement ou sur une plus longue durée, sorte de vertige. Ou d'effet de. Tant et tant de mots. Nouveaux, anciens, récupérés ou recyclés, inventés ou (pré)fabriqués. Pourquoi, pour répondre à quelle nécessité ce tant et tant de mots certainement spécialisés ou entendus dans une ou des acception(s) précise(s)? Comme si le «une/des" accolé à "acception(s) précise(s)" ne constituait pas déjà une incertitude, un flottement, disons un oxymore, noire clarté. Une sorte de vertige, c'est-à-dire une hésitation: vous fendez les cheveux en quatre, coiffeurs confus (se) dit lun, poli malgré tout, et, lettré aussi, pensant à Voltaire donnant sa description de l'écriture de Marivaux (et à tels autres chargeant Barthes, Lacan). Confus vous-même, de (se) répondre l'autre, également poli, il arrive que le langage courant, celui du cheveu entier et intégral, n'ait pas la transparence de ses apparences, perruques s'ajustant à bien des crânes. Dont celui du comédien, dirait Hamlet, words, words, words.

Bon. Vous savez bien qu'il y eut Byzance, les Grands Rhétoriqueurs, l'euphuisme (demandez à John Lyly où Pauline Harvey, siècle au choix) et la préciosité. Molière que vous aimez bien n’aidant pas, vous savez que le ridicule peut frapper rudement, persifleur ou pesant - et le byzantin offre une cible si préci(eu)se! Mais vous savez aussi que l'une des caractéristiques du gros bons sens est précisément d'être gros, sinon suffisant et rassurant. Comme vous savez encore que les mots, bavards, proliférants et créateurs, peuvent succomber à la douce manie de se gargariser d'eux-mêmes, suffisants, et de finir pour se prendre, magiciens de la pensée magique, pour la réalité elle-même. Apparence de dilemme. Bon.

Entre deux mots, words, words, choisir, comme toujours, le plus dynamique: celui qui favorise la nuance, la précision, donc la création, plutôt que celui qui, confortable et connu, sùr en apparence, entretient pourtant la confusion de ses sens indécis. On vous l'a dit ou vous l'avez appris, une esthétique cache, c'est-à-dire révèle, toujours une éthique. Terminer alors la discussion en relisant ce passage, en note dans Palimpsestes (p. 11), de Gérard Genette:

Décidément, rien ne s'arrangè du côté de la terminologie. Daucuns en concluront: "Vous n'avez qu'à parler comme tout le monde." Mauvais conseil: de ce côté-là. c'est encore pis. car l'usage est pavé de mots si familiers, si faussement transparents, qu'on les emploie souvent. pour théoriser à longueur de volumes ou de colloques, sans même songer à se demander de quoi lion parle. Nous rencontrerons très bientôt un exemple typique de ce psittacisme avec la notion, si lion peut dire, de 
parodie. Le "jargon" technique a du moins cet avantage qu'en général chacun de ses utilisateurs sait et indique quel sens il donne à chacun de ses termes.

Alors justement, essayer d'arranger les choses du côté de, telle pouvant bien être le fonction des glossaires. D'autant plus, comme le souligne Genette, que l'utilisateur du «jargon» technique donne habituellement, avantage certain, le sens des termes dudit. Alors?

R.B./A.G. 